\title{
Diversity of the basic defect of homozygous CFTR mutation genotypes in humans
}

\author{
F Stanke, ${ }^{1,2} \mathrm{M}$ Ballmann, ${ }^{2}$ I Bronsveld, ${ }^{4} \mathrm{~T}$ Dörk, ${ }^{3} \mathrm{~S}$ Gallati, ${ }^{5} \mathrm{U}$ Laabs, ${ }^{1} \mathrm{~N}$ Derichs, ${ }^{2}$ \\ M Ritzka, ${ }^{1,2} \mathrm{H}$-G Posselt, ${ }^{6}$ H K Harms, ${ }^{7}$ M Griese, ${ }^{7}$ H Blau, ${ }^{8}$ G Mastella, ${ }^{9} \mathrm{~J} \mathrm{Bijman},{ }^{10}$ \\ H Veeze, ${ }^{11}$ B Tümmler ${ }^{1,2}$
}

${ }^{1}$ Klinische Forschergruppe and Abteilungen für; ${ }^{2}$ Pädiatrische Pneumologie und Neonatologie and; ${ }^{3}$ Gynäkologie und Geburtshilfe, Medizinische Hochschule Hannover, Hannover, Germany;

${ }^{4}$ Department of Pulmonology and Tuberculosis, Universitair Medisch Centrum Utrecht, Utrecht, The Netherlands;

${ }^{5}$ Abteilung für Humangenetik, Medizinische

Universitätskinderklinik, Inselspital, Universität Bern, Bern, Switzerland; ${ }^{6}$ UniversitätsKinderklinik, Johann-WolfgangGoethe Universität, Frankfurt/ Main, Germany; ${ }^{7}$ Dr von Haunersches Kinderspital, Ludwig-Maximilians-Universität, Munich, Germany; ${ }^{8}$ Pulmonary and Cystic Fibrosis Unit,

Schneider Children's Medical Center of Israel, Petah-Tikva, and Sackler School of Medicine, Tel-Aviv University, Tel-Aviv, Israel; ${ }^{9}$ Cystic Fibrosis Center, Ospedale Civile Maggiore,

Piazzale Stefani, Verona, Italy;

${ }^{10}$ Erasmus University

Rotterdam, Department of

Neurosciences, Rotterdam, The

Netherlands; ${ }^{11}$ Stichting

Diabeter, Rotterdam, The

Netherlands

Correspondence to:

Dr Burkhard Tümmler, Klinische Forschergruppe, OE 6710,

Medizinische Hochschule

Hannover, Carl-Neuberg-Str. 1, D-30625 Hannover, Germany; tuemmler.burkhard@mh-

hannover.de

Received 31 July 2007 Revised 18 September 2007 Accepted 24 September 2007

\section{UN LOCK:D}

This paper is freely available online under the BMJ Journals unlocked scheme, see http:// jmg.bmj.com/info/unlocked.dtl

\section{ABSTRACT}

Background: Knowledge of how CFTR mutations other than F508del translate into the basic defect in cystic fibrosis (CF) is scarce due to the low incidence of homozygous index cases.

Methods: 17 individuals who are homozygous for deletions, missense, stop or splice site mutations in the CFTR gene were investigated for clinical symptoms of CF and assessed in CFTR function by sweat test, nasal potential difference and intestinal current measurement.

Results: CFTR activity in sweat gland, upper airways and distal intestine was normal for homozygous carriers of G314E or L997F and in the range of F508del homozygotes for homozygous carriers of E92K, W1098L, R553X, R1162X, CFTRdele2(ins186) or CFTRdele2,3(21 kb). Homozygotes for M1101K, 1898+3 A-G or 3849+10 kb C-T were not consistent CF or non-CF in the three bioassays. 14 individuals exhibited some chloride conductance in the airways and/or in the intestine which was identified by the differential response to CAMP and DIDS as being caused by CFTR or at least two other chloride conductances.

Discussion: CFTR mutations may lead to unusual electrophysiological or clinical manifestations. In vivo and ex vivo functional assessment of CFTR function and indepth clinical examination of the index cases are indicated to classify yet uncharacterised CFTR mutations as either disease-causing lesions, risk factors, modifiers or neutral variants.

Cystic fibrosis (CF) is an autosomal recessive disorder of all exocrine glands and is caused by mutations in the Cystic Fibrosis Transmembrane Conductance Regulator (CFTR) gene. ${ }^{1}$ CFTR is localised in the apical membrane of epithelial cells and confers cAMP-activatable transport of chloride, bicarbonate and glutathione. ${ }^{1}$ The basic defect in CF impairs the apical permeability for chloride and is assessed in humans by the increased chloride concentrations in sweat, ${ }^{2}$ the low chloride conductance of upper airway epithelium ${ }^{3}$ or the lower chloride secretory response of the intestinal epithelium to secretagogues. ${ }^{4}$

The major mutation F508del is found on about $70 \%$ of CF alleles, but all other $(>1300)$ known disease-causing lesions are rare with a frequency ranging from $2 \%$ to less than $0.01 \%$ in Caucasian populations (http://www.genet.sickkids.on.ca/ $\mathrm{cftr} /)^{5}$ Hence the CFTR phenotype of most mutations other than F508del has been investigated in heterologous expression systems ${ }^{6}$ rather than by in vivo or ex vivo analysis of patients' material, because almost all patients with CF are either homozygous for F508del or compound heterozygous for two different CFTR mutations. The investigation of compound heterozygous individuals does not provide unequivocal information about the phenotype of the individual mutation and consequently the in vivo phenotype of a CFTR mutation can best be studied in homozygotes for a particular CFTR mutation.

This report describes the basic defect of individuals who are homozygous for non-F508del CFTR mutations. These rare index cases were identified during the last 15 years by CFTR mutation analysis of large patient populations in Germany, Italy and Israel. A cohort of F508del homozygous sibpairs from nine European countries ${ }^{7}$ was used as reference group. The patients' defective chloride transport across the apical membrane of epithelial cells was measured by the physiological assays employed when diagnosing CF-that is, the sweat test, ${ }^{2}$ the nasal potential difference (NPD) ${ }^{3}$ and intestinal current measurements (ICM) of freshly excised rectal suction biopsies. ${ }^{4}$ CFTR function was not detectable in individuals who harbour two CFTR null alleles and close to normal in two individuals who are homozygous for non-conservative amino acid substitutions.

\section{SUBJECTS AND METHODS}

\section{Subjects}

The index cases (table 1) selected from CF centres in Germany, Italy and Israel were investigated at the CF centres in Verona (patients 3 and 4) or Hannover (all other patients). Informed consent was obtained from all patients and at least one parental guide in case of minors. This study was approved by the ethics committee of the Medizinische Hochschule Hannover (study no. 1226). All subjects except patient 2 were offspring of consanguineous marriages which was documented by the parental status of first or second generation cousins in the family tree (patients 1, $3-14$ ) or by the overrepresentation of homozygous marker genotypes (patients 15-17). Before the date of the investigation of the basic defect by NPD and/or ICM, all index cases had been diagnosed with CF. The diagnosis had been based on clinical symptoms compatible with CF and/or a positive family anamnesis, chloride concentrations in the sweat test $>40 \mathrm{mval} / \mathrm{l}$ and/or two CFTR sequence variations not yet described in healthy control populations. The standardised clinical examination at the day of assessment ${ }^{8}$ included family anamnesis, patient's history, acute clinical symptoms 
and medication, a physical examination, documentation of meconium ileus, meconium ileus equivalent, hepatobiliary disease, diabetes mellitus, fertility, other diseases, anthropometry, determination of pancreatic elastase in stool as an index for the exocrine pancreatic status, a lung function test (the forced vital capacity and the forced expiratory volume in $1 \mathrm{~s}$ were determined by spirometry and expressed as a predictive value based on Knudson's formulas ${ }^{9}$ ), bacteriology of sputum or deep throat swab, serum IgG and IgE and antipseudomonal IgG. After the clinical examination a Gibson-Cooke pilocarpine iontophoresis sweat test, ${ }^{2} \mathrm{NPD}^{3}$ and $\mathrm{ICM}^{4}$ measurements were performed within the next $72 \mathrm{~h}$.

\section{Mutation analysis at the CFTR locus}

A cascade approach was taken to identify CFTR mutations in genomic DNA from nuclear blood cells. ${ }^{10}{ }^{11} \mathrm{~K}$-EDTA blood samples were taken from the patient and, at the Hannover site, also from the parents. First, frequent CFTR mutations were directly tested by established polymerase chain reaction (PCR)based protocols guided by the parental CFTR haplotypes of the index case. Next, the 27 exons of the CFTR gene together with their flanking intron regions were amplified separately by PCR. Before 1995, sequence variations were sought by single strand conformation polymorphism (SSCP) or restriction enzyme based analysis of PCR product. All non-F508del mutations detected by direct testing or anomalous migration behaviour in SSCP were confirmed by direct genomic sequencing of the respective exon. Starting by 1995, SSCP was omitted and the whole coding and flanking intron sequences were determined by direct genomic sequencing as the second step. Finally, specimens which were refractory to amplification by PCR were scanned for genomic rearrangements by Southern hybridisation with PCR generated genomic probes encompassing the respective exon and flanking intron sequences. By this cascade approach a $100 \%$ detection rate of two CFTR mutations had been achieved in a cohort of 330 exocrine pancreas insufficient German patients with CF. Of 52 exocrine pancreas sufficient subjects with CF, two CFTR mutations were detected in 42 patients and only one mutation in 10 patients.

\section{Transepithelial NPD measurements $^{3} 7$}

Access to the subcutaneous space was obtained by a needle filled with $\mathrm{NaCl}$ solution inserted subcutaneously into the forearm. The lower nasal turbinate was superfused with a polyethylene tube (PE-50) connected via syringes to the various superfusing solutions. Both the needle and the PE-50 tubing were connected to a high impedance voltmeter via $\mathrm{Ag} / \mathrm{AgCl}$ electrodes and agar/saline-filled salt bridges. The basal PD was measured by superfusing $\mathrm{NaCl}$ buffer $\mathrm{A}(120 \mathrm{mM} \mathrm{NaCl}, 25 \mathrm{mM}$ NaGluconate, $0.4 \mathrm{mM} \mathrm{NaH}_{2} \mathrm{PO}_{4}, 2.4 \mathrm{mM} \mathrm{Na}_{2} \mathrm{HPO}_{4}$ ) over the nasal mucosa. Subsequently, electrogenic sodium absorption was blocked with $0.1 \mathrm{mM}$ amiloride in buffer $\mathrm{A}$. To determine the basal chloride conductance, the nasal mucosa was superfused with buffer $\mathrm{B}\left(145 \mathrm{mM} \mathrm{NaGluconate,} 0.4 \mathrm{mM} \mathrm{NaH}_{2} \mathrm{PO}_{4}\right.$, $2.4 \mathrm{mM} \mathrm{Na}_{2} \mathrm{HPO}_{4}, 0.1 \mathrm{mM}$ amiloride). Finally the responsiveness to $0.1 \mathrm{mM}$ isoproterenol in buffer $\mathrm{B}$, which typically activates CFTR chloride channels, was tested.

\section{Intestinal current measurements}

ICM was performed on freshly obtained rectal suction biopsies in a micro-Ussing chamber according to our published protocol. ${ }^{4}$ The biopsies equilibrated in Meyler's buffer (gassed with $\left.95 \% \mathrm{O}_{2}-5 \% \mathrm{CO}_{2}\right)^{4}$ were sequentially exposed to the mucosal
$(M)$ and/or serosal $(S)$ side to: (1) amiloride $\left(10^{-4} \mathrm{M}, M\right)$; (2) indomethacin $\left(10^{-5} \mathrm{M}, M+S\right)$, to reduce basal chloride secretion by inhibiting the endogenous prostaglandin formation; (3) carbachol $\left(10^{-4} \mathrm{M}, S\right)$, to initiate the cholinergic $\mathrm{Ca}^{2+}$-linked chloride secretion; (4) forskolin $\left(10^{-5} \mathrm{M}, M+S\right)$ together with 8bromo-cAMP $\left(10^{-3} \mathrm{M}, M+S\right)$, to open cAMP-dependent $\mathrm{Cl}^{-}$ channels like CFTR; (5) 4,4'-diisothiocyanatostilbene-2,2'-disulfonic acid (DIDS, $2.10^{-4} \mathrm{M}, M$ ), to inhibit DIDS-sensitive $\mathrm{Cl}^{-}$transporters like the $\mathrm{Ca}^{2+}$-dependent $\mathrm{Cl}^{-}$channels and the ORCC; (6) histamine $\left(5.10^{-4} \mathrm{M}, S\right)$, to reactivate the $\mathrm{Ca}^{2+}$ dependent chloride secretory pathway. ${ }^{4}$

\section{RESULTS}

Seventeen individuals homozygous for a non-F508del CFTR mutation were recruited for the study. The patients' clinical characteristics and the sweat test, NPD and ICM values are shown in tables 1-3. The electrophysiological phenotype of the patients' basic defect (table 4) was compared with that of F508del homozygous CF siblings who had been studied previously by the same protocol and the same core team of investigators. ${ }^{7}$ All F508del homozygotes had CF-typical sweat test, NPD and ICM values (tables 2 and 3 ). ${ }^{7}$

Expression of functional CFTR was expected to be absent in patients harbouring two CFTR null alleles. The homozygotes for the large out-of-frame $21 \mathrm{~kb}$ deletion of exons 2 and $3^{12}$ of the CFTR gene (Fig 1B) or the nonsense mutation R553X showed indeed full-blown CFTR loss-of-function phenotypes in the bioassays. The two R1162X homozygous patients, however, had some chloride secretory activity in their intestine that consisted of both DIDS-sensitive and DIDS-insensitive components (fig 1D, tables 4 and 5).

Residual chloride conductance was detected in subjects with splice site mutations that permit production of some wild type CFTR. The mutation $3849+10 \mathrm{~kb}$ C-T is known to activate a cryptic splice acceptor site in intron 19 and leads to variable levels of both aberrant and correct CFTR mRNA transcripts modulated by splicing factors in a tissue dependent manner. ${ }^{13} 14$ Accordingly we measured sweat chloride concentrations and basal NPD values in both the normal and the CF range in two $3849+10 \mathrm{~kb}$ C-T homozygous siblings, whereas in contrast only minute chloride secretion like in most F508del homozygotes was detected in the ICM. The donor splice mutation 1898+3 A$\mathrm{G}$ in intron 12 of $C_{F T R^{15}}$ affects a not obligatorily conserved position. The homozygous index case presented an electrophysiological phenotype intermediate between CF and non-CF (tables 1-3). The DIDS-insensitive chloride secretory responses to cAMP, carbachol and histamine in the ICM were higher than those ever seen in patients with an established CF diagnosis, but were lower than measured before in all non-CF controls (fig 1B). Consistent with this intermediate phenotype of the basic defect, the currently 15-year-old patient developed only minimal symptoms of CF respiratory and gastrointestinal disease and required virtually no treatment.

The in-frame deletion of exon 2 detected by the authors within the frame of this study showed a variable manifestation of the basic defect with residual cAMP-activatable DIDSsensitive or DIDS-insensitive chloride secretion in two of the three patients (tables 4 and 5). Absence or presence of residual chloride secretory activity in the intestine was associated with severe or very mild courses of clinical CF disease in the three subjects who received no adequate symptomatic therapy of CF for prolonged periods of time. The ICM data suggest that the CFTR mutant lacking exon 2 may confer some residual chloride secretory activity to the intestine. 


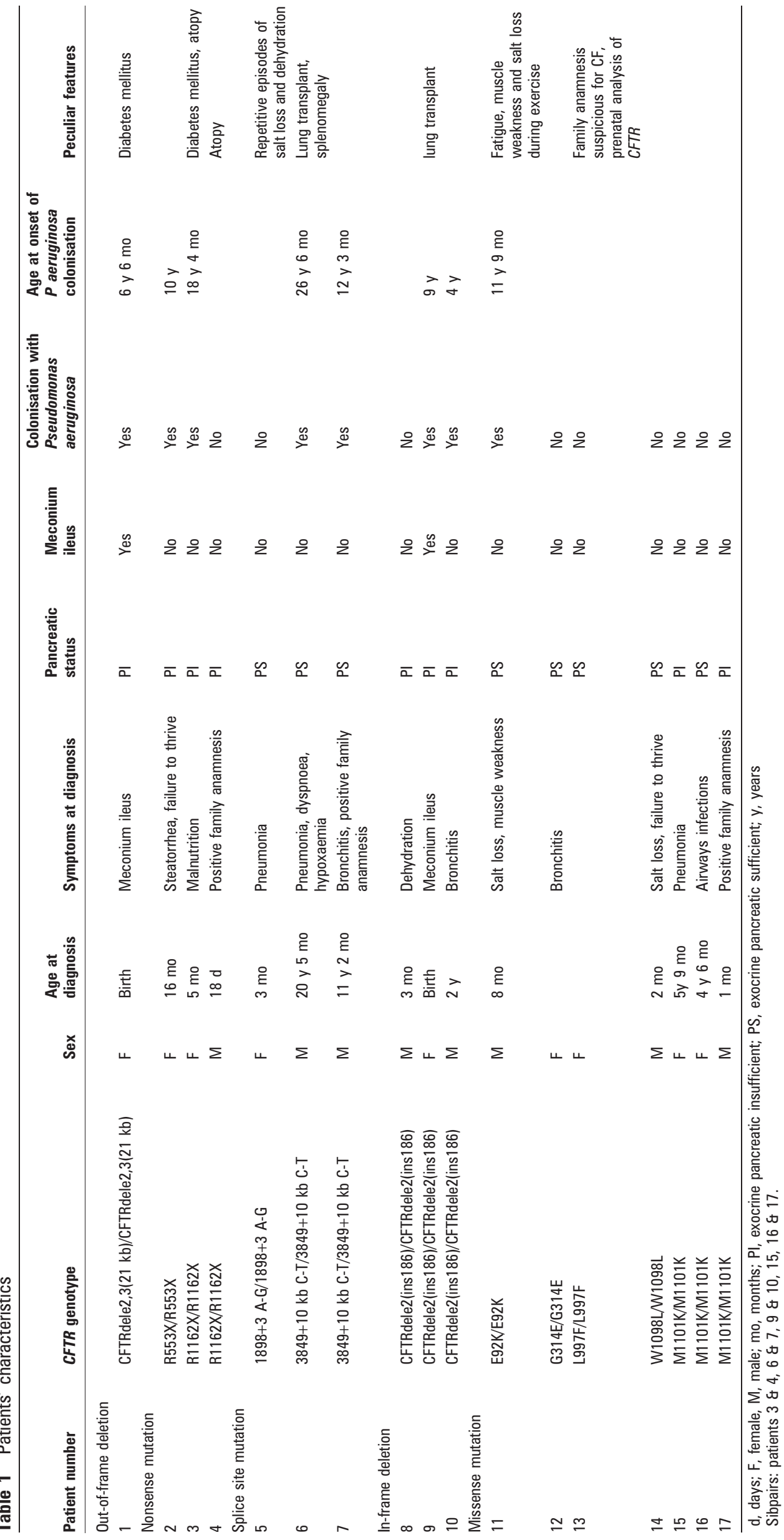


Table 2 Assessment of basic defect (A): sweat tests and nasal potential difference (NPD) measurements (mV)

\begin{tabular}{|c|c|c|c|c|c|c|}
\hline \multirow[b]{2}{*}{ Patient number } & \multirow[b]{2}{*}{ CFTR genotype } & \multicolumn{2}{|c|}{ Sweat chloride concentration (mval/l) } & \multirow[b]{2}{*}{$\begin{array}{l}\text { Basal PD } \\
(\mathrm{mV})\end{array}$} & \multicolumn{2}{|c|}{ Change in PD (mV) } \\
\hline & & $\begin{array}{l}\text { Day of } \\
\text { assessment }\end{array}$ & $\begin{array}{l}\text { Prior tests } \\
\text { (age) }\end{array}$ & & Amiloride & $\begin{array}{l}\text { Chloride-free + } \\
\text { isoproterenol }\end{array}$ \\
\hline \multicolumn{7}{|c|}{ Out-of-frame deletion } \\
\hline \multicolumn{7}{|c|}{ Nonsense mutation } \\
\hline 2 & R553X/R553X & 96 & $100(16 \mathrm{mo})$ & -62 & 34 & -7 \\
\hline 3 & $\mathrm{R} 1162 \mathrm{X} / \mathrm{R} 1162 \mathrm{X}$ & 98 & 110 (2 y $1 \mathrm{mo})$ & -48 & 23 & -4 \\
\hline 5 & $1898+3 \mathrm{~A}-\mathrm{G} / 1898+3 \mathrm{~A}-\mathrm{G}$ & 73 & 69 (4 mo) & -33 & 21 & -3 \\
\hline \multirow[t]{2}{*}{6} & $3849+10 \mathrm{~kb} \mathrm{C}-\mathrm{T} / 3849+10 \mathrm{~kb} \mathrm{C}-\mathrm{T}$ & 92 & $64(20$ y $5 \mathrm{mo})$ & -44 & 30 & -12 \\
\hline & & & 49 (28 y 4 mo) & & & \\
\hline 7 & $3849+10 \mathrm{~kb} \mathrm{C}-\mathrm{T} / 3849+10 \mathrm{~kb} \mathrm{C}-\mathrm{T}$ & 20 & $50(11$ y $2 \mathrm{mo})$ & -27 & 12 & +3 \\
\hline \multicolumn{7}{|l|}{ In-frame deletion } \\
\hline 11 & E92K/E92K & 118 & $93(8 \mathrm{mo})$ & -52 & 20 & -11 \\
\hline 12 & G314E/G314E & 15 & 43 (6 y $2 \mathrm{mo})$ & -19 & 4 & -16 \\
\hline 13 & L997F/L997F & 8 & & & & \\
\hline 14 & W1098L/W1098L & 107 & $118(2 \mathrm{mo})$ & & & \\
\hline 15 & M1101K/M1101K & 108 & 120 & -56 & 33 & -16 \\
\hline 16 & M1101K/M1101K & 130 & 120 & -64 & 26 & -15 \\
\hline \multirow[t]{3}{*}{17} & M1101K/M1101K & 118 & & -29 & 13 & -10 \\
\hline & F508del/F508del $(\mathrm{n}=74)^{7}$ & \multicolumn{2}{|c|}{$106 \pm 22$} & $-56 \pm 10$ & $28 \pm 9$ & $-8 \pm 5$ \\
\hline & non-CF $(n=25)$ & \multicolumn{2}{|c|}{$16 \pm 9$} & $-20 \pm 10$ & $11 \pm 6$ & $-30 \pm 8$ \\
\hline
\end{tabular}

Sibpairs: patients 3 \& 4,6 \& 7,9 \& 10,15, 16 \& 17.

Seven study participants were homozygous for a missense mutation in the CFTR gene (table 4). By the time of writing, none of the 5- to 23-year-old individuals had yet experienced any severe exacerbation of CF pulmonary or gastrointestinal disease. The homozygotes for $\mathrm{E} 92 \mathrm{~K},{ }^{16}$ W1098L or M1101K ${ }^{17}$ showed highly elevated sweat chloride concentrations in the CF range on several occasions, whereas the homozygotes for G314E ${ }^{18}$ or L997F ${ }^{19} 20$ had normal sweat electrolytes like nonCF healthy controls (table 2). The NPD responses were heterogeneous in the group. Only the E92K homozygote showed the CF pattern of a large response to amiloride and of a low chloride diffusion potential. The missense mutation E92K results from a G-to-A transition in the first base of exon 4 and hence may not also lead to the substitution of a glutamate by a lysine but also may affect splicing as it has been observed for the stop mutation E92X. ${ }^{21}$ The G314E and the M1101K homozygotes exhibited an intermediate chloride secretory phenotype between typical CF and typical non-CF. Rectal epithelial tissue from all seven subjects exhibited substantial DIDS-insensitive chloride secretory responses indicating that all analysed CFTR mutants can transport chloride. The transport rates were in the upper CF range (E92K, W1098L, one M1101K sibling), in the intermediate range between CF and non-CF (the other two M1101K siblings) or in the normal range (L997F, G314E) (fig 1C). The tissue specimens from two M1101K homozygous siblings expressed two patterns of chloride secretory responses that are consistent with the presence of both CFTR and the alternative chloride channel ORCC (fig 1E, table 5). ${ }^{7}$ Since the outcome of NPD, ICM, sweat test and clinical examination was normal in the G314E or L997F homozygotes, the diagnosis of CF that had been based on mutation reports in the literature, ${ }^{18} 19$ positive family anamnesis or suggestive respiratory symptoms, was withdrawn for these two individuals.

\section{DISCUSSION}

This first study of how non-F508del homozygous CFTR genotypes translate into the basic defect in the major affected organs in vivo, uncovered the full range from complete loss-offunction to normal non-CF phenotypes. All patients except patient 2 descended from consanguineous marriages characterised by an overrepresentation of homozygous genotypes. Hence we expected the sibpairs in our cohort to be concordant in their manifestations of aberrant epithelial chloride conductance, but this was not the case. The siblings showed an individual rather than a shared electrophysiological signature in NPD and ICM (tables 2 and 3), suggesting that individual factors modify the CF phenotype at the level of the basic defect even though it is more closely related to the mutation genotype than any clinical symptom.

More than $90 \%$ of CF patients are homozygous or compound heterozygous for F508del, ${ }^{1}$ and consequently our perception of CF disease is dominated by this major mutation. Loss-offunction mutations such as CFTRdele2,3(21 kb) or R553X were not distinguishable in their clinical phenotypes from those of F508del homozygotes, although the consequences at the molecular level such as nonsense mediated decay and exon skipping ${ }^{22}$ or defective maturation and trafficking of protein ${ }^{1}$ are different.

All other CFTR mutations investigated in this study translated into facets of disease and basic defect that are atypical for the most common genotype. Splice site mutations, for example, were associated with progressive lung disease and a 


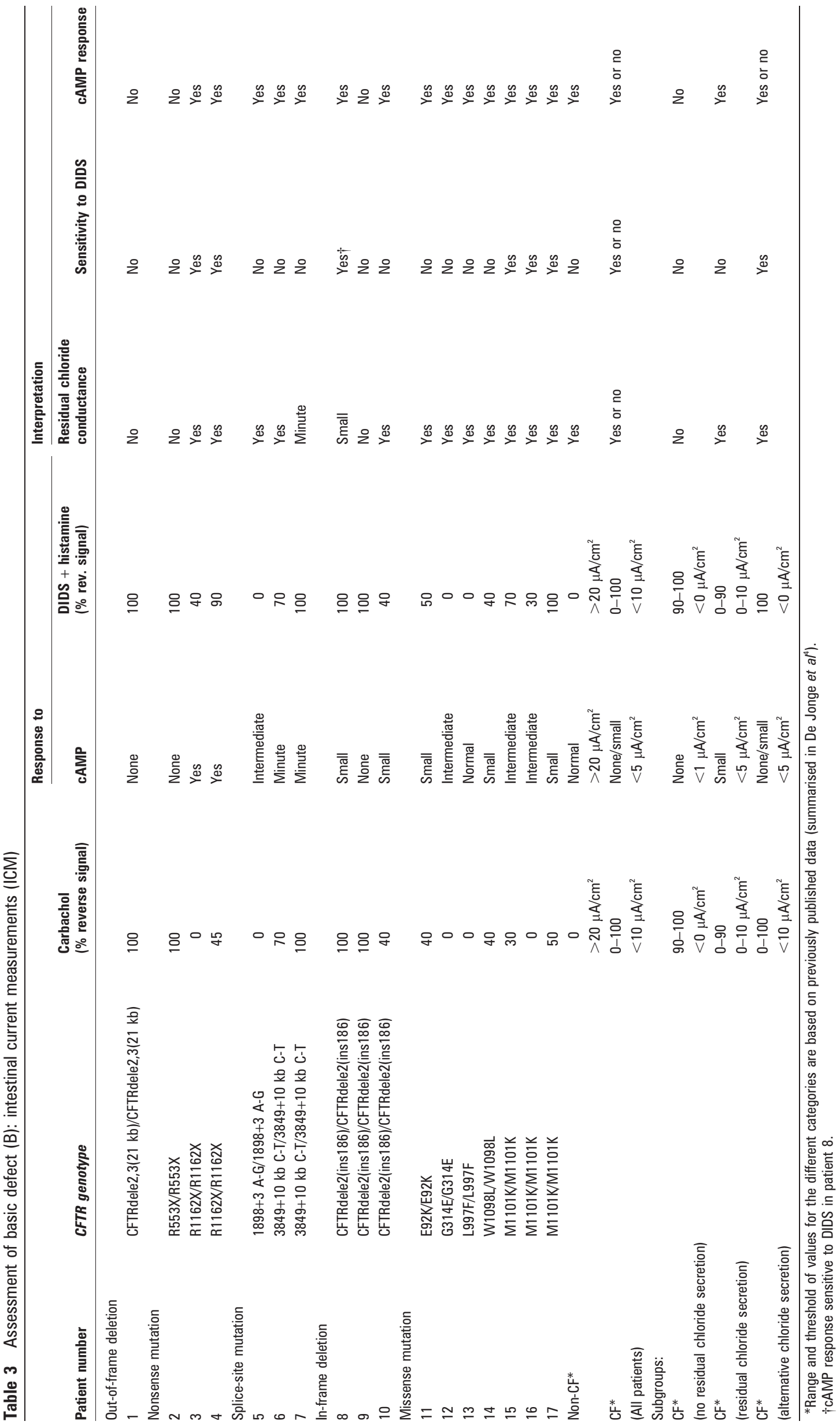

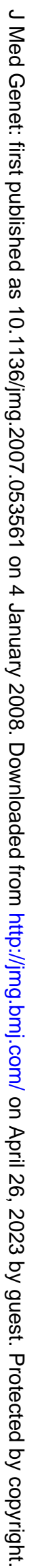




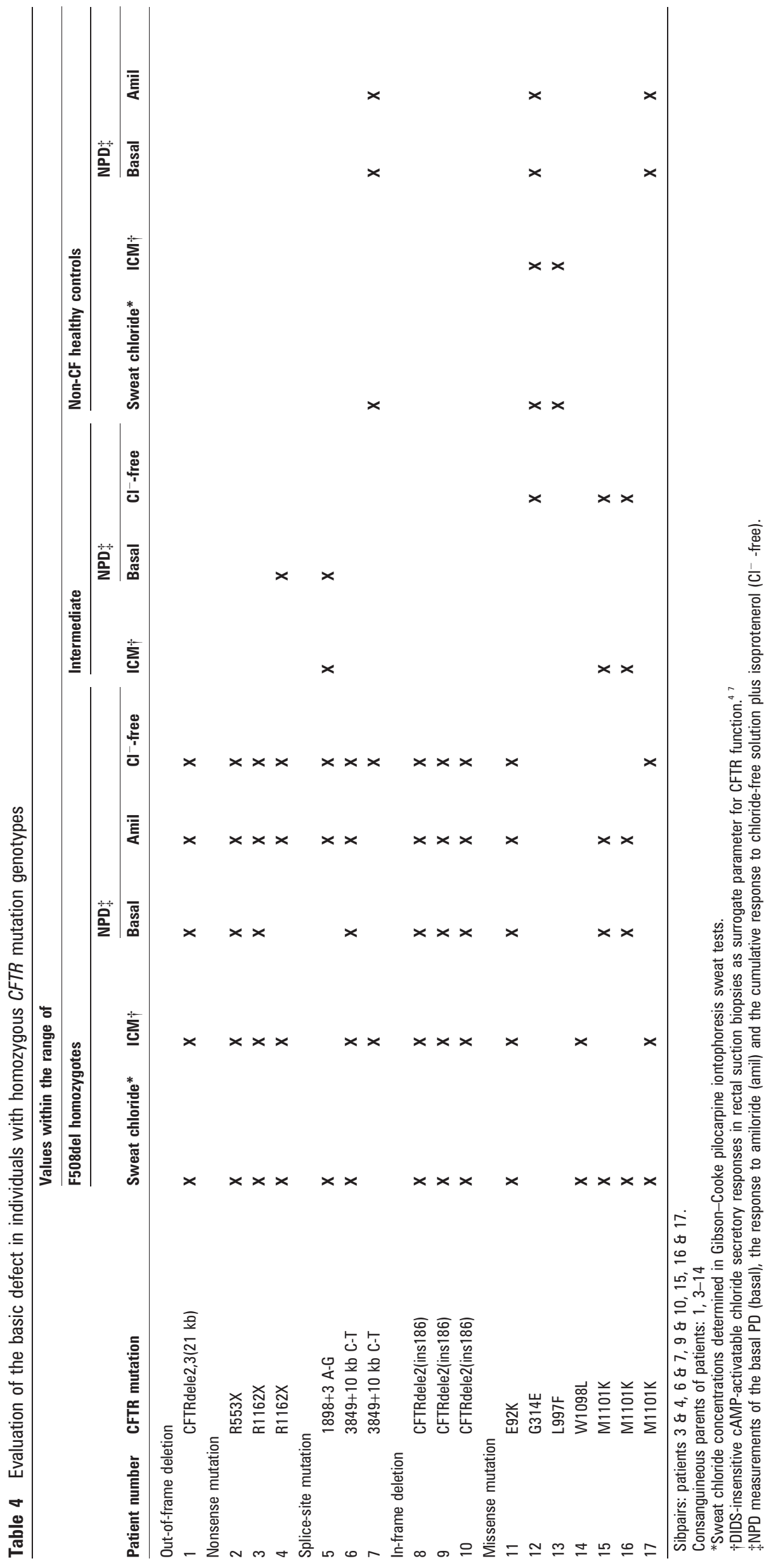

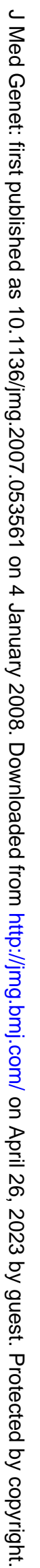



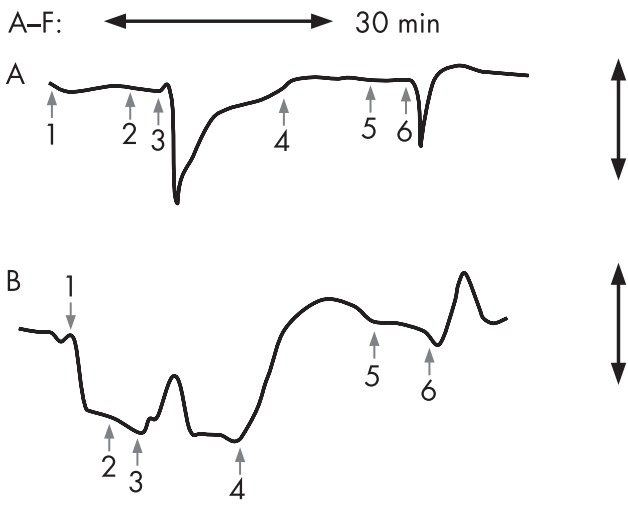

C

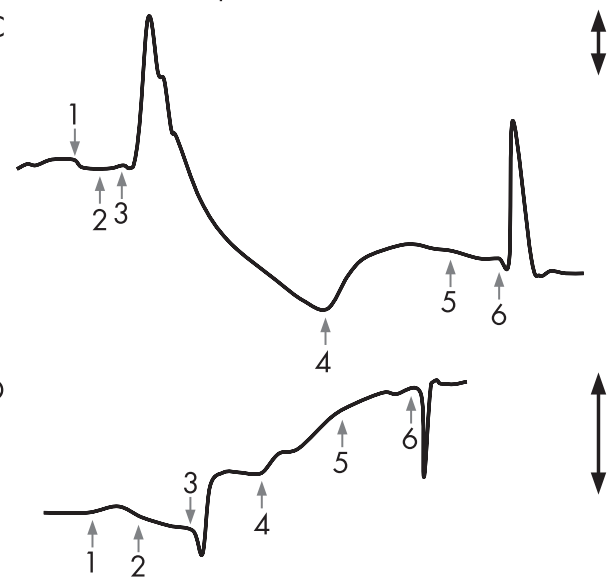

E

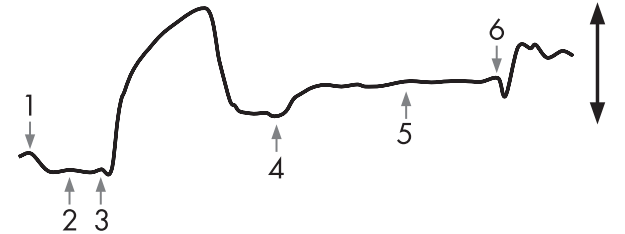

$\mathrm{F}$

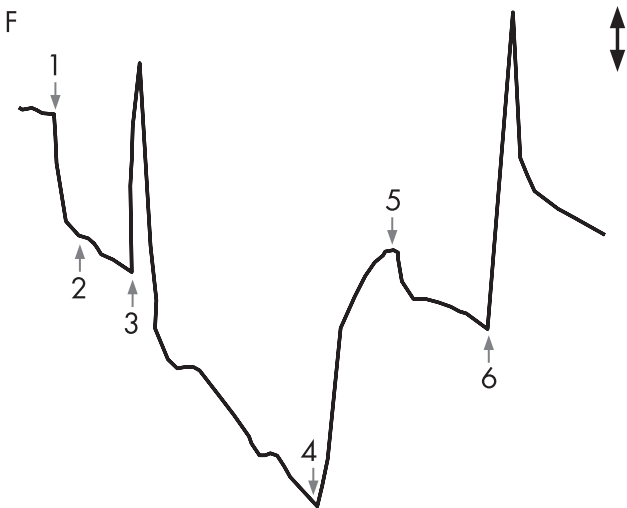

Figure 1 Recordings of short circuit currents. ICM recordings of individuals homozygous for CFTRdele2,3(21 kb) (A), 1898+3 A-G (B), G314E (C), R1162X (D), M1101K (E) or of a healthy non-CF individual (F). The horizontal double-headed arrow corresponds to a recording time of 30 min and each vertical double-headed arrow to a current of $10 \mu \mathrm{A} /$ $\mathrm{cm}^{2}$. Please note the twofold contracted scale for tracings $C$ and $F$. The arrows indicate the addition of amiloride (1), indomethacin (2), carbachol (3), cAMP/forskolin (4), DIDS (5) and histamine (6). The tracings show no (A), intermediate (B) or normal CFTR activity (C, F). The chloride secretory responses of patients $D$ and $E$ are partially caused by the expression of alternative chloride channels.

normal sweat test in case of $3849+10 \mathrm{~kb} \mathrm{C}-\mathrm{T}^{13}$ and with minimal disease and substantial chloride secretion beyond the CF range in the ICM in case of $1898+3 \mathrm{~A}-\mathrm{G}$.
Table 5 Patients' patterns of residual chloride secretory responses in intestinal current measurements (ICM)

\begin{tabular}{|c|c|c|c|c|}
\hline \multirow{2}{*}{$\begin{array}{l}\text { Chloride } \\
\text { secretory } \\
\text { response }\end{array}$} & \multicolumn{2}{|c|}{ Sensitivity to } & \multirow{2}{*}{$\begin{array}{l}\text { Interpretation } \\
\text { Ion channel }\end{array}$} & \multirow[b]{2}{*}{ Patient number } \\
\hline & cAMP & DIDS & & \\
\hline Yes & Yes & No & CFTR & $\begin{array}{l}3,4,5,6,7,10,11,12,13,14 \\
15,16,17\end{array}$ \\
\hline Yes & Yes & Yes & CACC/ORCC & $3,4,8,15,16,17$ \\
\hline No & & & & $1,2,9$ \\
\hline
\end{tabular}

Missense mutations are a guide to dissect the function of CFTR motifs and domains. E92K and D110H (data not shown) are located in the first ectoplasmic loop. The index cases were prone to severe salt loss upon exposure to heat or exercise, but otherwise are overweight and have normal lung function. Hence, the integrity of the loop at these positions seems to be essential for the reabsorption of salt from the sweat duct, but less relevant for ion secretion in airways and intestine.

The mutations W1098L and M1101K reside in the cytoplasmic loop 4 (residues 1035-1102). Heterologously expressed, recombinant mutants W1098R and M1101K were defective in CFTR maturation and non-functional in anion efflux assays. ${ }^{6}$ In contrast, the four homozygous patients unequivocally demonstrated substantial residual chloride conductance in the NPD and ICM bioassays (table 4). In vitro and in vivo CFTR mutant phenotypes do not match. Rescue mechanisms are probably operating in the patients which were absent in the heterologous host cells in vitro. This example makes the point that in vitro findings on recombinant mutants should be interpreted with caution when utilised for counselling of patients and their relatives.

The non-conservative amino acid substitutions L997F and G314E did not impair chloride conductance in sweat glands, airways and intestine. The normal phenotype of the glycine-toglutamate substitution is particularly striking. The CFTR mutation database lists 20 missense mutations with a change of glycine to an acidic amino acid or vice versa, three of which are classified as benign sequence variants and eight of which as disease-causing. Several well characterised severe mutations occur in the evolutionarily conserved Walker (G1244E, G1249E) or dodecapeptide motifs (G551D, G1349D) of the ABC transporter CFTR. ${ }^{1}$ The missense mutants $\mathrm{G}^{2} 22 \mathrm{D}^{23}$ in the regulatory domain and $\mathrm{G} 314 \mathrm{E}$ in the fifth transmembrane region led to no clinical symptoms of $\mathrm{CF}$. The pathogenetic role of nine mutations is still unresolved. The same amino acid substitution thus affects CFTR function to a variable extent depending on its localisation within the protein. In other words, the molecular pathology of a missense mutant is hard to predict, because CFTR topology, function and processing are complex. If mutation analysis uncovers an uncommon and/or yet uncharacterised missense mutation, diagnostic bioassays and in-depth clinical examination of the index cases need to be pursued in order to classify the clinical impact of an amino acid substitution as either neutral, benign or severe.

Our highly selected study cohort of individuals with rare homozygous CFTR genotypes showed an association with mild or asymptomatic clinical manifestation if CFTR function was in the intermediate or normal range in both NPD and ICM. This positive correlation between the amount of residual CFTR function and milder disease did not, however, apply to the individual case, if NPD and/or ICM values were within the CF range. The two $3849+10 \mathrm{~kb}$ C-T homozygotes who started to develop symptoms of CF respiratory disease during adolescence, 
and were diagnosed at the oldest age in our cohort, showed the most severe progression of disease during adulthood leading to lung transplantation and death; however, patients 1 and 2, with loss-of-function electrophysiological signature, experienced at the same age a comparatively high quality of life with no significant deterioration of their respiratory or gastrointestinal disease.

In summary, while our study could clearly distinguish individuals with asymptomatic or atypical CF, no prognostic value could be derived for the individual case from the amount of residual CFTR-mediated chloride secretion if the results were within the CF range. This conclusion should be borne in mind during genetic counselling of patients or parental guides that typically takes place early in the life of a CF patient.

Acknowledgements: We would like to thank patients and their parental guides for the participation in the study and our colleagues at the CF clinics in Bonn, Düsseldorf, Esslingen, Frankfurt, Gießen, Göttingen, München, Münster, Tel Aviv and Verona for organizational help. The study was supported by a grant from the Deutsche Forschungsgemeinschaft to BT (SFB 621, project C7). The generous support of participating families by the Christiane Herzog Stiftung is gratefully acknowledged.

Competing interests: None.

\section{REFERENCES}

1. Bush A, Alton EWFW, Davies JC, Griesenbach U, Jaffe A, eds. Cystic fibrosis in the 21st century, Part 1. Basel, Switzerland: Karger, 2006:2-114.

2. Gibson LE, Cooke RE. A test for concentration of electrolytes in sweat in cystic fibrosis of the pancreas utilizing pilocarpine by iontophoresis. Pediatrics 1959;23:5459 .

3. Schüler D, Sermet-Gaudelus I, Wilschanski M, Ballmann M, Dechaux M, Edelman A, Hug M, Leal T, Lebacq J, Lebecque P, Lenoir G, Stanke F, Wallemacq P, Tümmler B, Knowles MR. Basic protocol for transepithelial nasal potential difference measurements. J Cyst Fibros 2004;3(Suppl 2):151-5.

4. De Jonge HR, Ballmann M, Veeze H, Bronsveld I, Stanke F, Tümmler B, Sinaasappel M. Ex vivo CF diagnosis by intestinal current measurements (ICM) in small aperture, circulating Ussing chambers. J Cyst Fibros 2004;3(Suppl 2):159-63.

5. Bobadilla JL, Macek M Jr, Fine JP, Farrell PM. Cystic fibrosis: a worldwide analysis of CFTR mutations--correlation with incidence data and application to screening. Hum Mutat 2002:19:575-606.

6. Seibert FS, Linsdell P, Loo TW, Hanrahan JW, Clarke DM, Riordan JR. Diseaseassociated mutations in the fourth cytoplasmic loop of cystic fibrosis transmembrane conductance regulator compromise biosynthetic processing and chloride channel activity. J Biol Chem 1996;271:15139-45.

7. Bronsveld I, Mekus F, Bïman J, Ballmann M, de Jonge HR, Laabs U, Halley DJ, Ellemunter H, Mastella G, Thomas S, Veeze HJ, Tümmler B. Chloride conductance and genetic background modulate the cystic fibrosis phenotype of Delta F508 homozygous twins and siblings. J Clin Invest 2001;108:1705-15.

8. Association Francaise de Lutte contre la Mucoviscidose. Genotype-phenotype correlations in CF. Paris: AFLM, 1994.

9. Knudson RJ, Lebowitz MD, Holberg CJ, Burrows B. Changes in the normal maximal expiratory flow-volume curve with growth and aging. Am Rev Respir Dis 1983:127:725-34.

10. Dörk T, Mekus F, Schmidt K, Bosshammer J, Fislage R, Heuer T, Dziadek V, Neumann T, Kalin N, Wulbrand U, Wulf B, von der Hardt H, Maaß G, Tümmler B.
Detection of more than 50 different CFTR mutations in a large group of German cystic fibrosis patients. Hum Genet 1994;94:533-42.

11. Liechti-Gallati S, Schneider V, Neeser D, Kraemer R. Two buffer PAGE systembased SSCP/HD analysis: a general protocol for rapid and sensitive mutation screening in cystic fibrosis and any other human genetic disease. Eur J Hum Genet 1999; 7:590-8.

12. Dörk T, Macek M Jr, Mekus F, Tümmler B, Tzountzouris J, Casals T, Krebsová A Koudová M, Sakmaryová I, Macek M Sr, Vávrová V, Zemková D, Ginter E, Petrova NV Ivaschenko T, Baranov V, Witt M, Pogorzelski A, Bal J, Zékanowsky C, Wagner K, Stuhrmann M, Bauer I, Seydewitz HH, Neumann T, Jakubiczka S, Kraus C, Thamm B, Nechiporenko M, Livshits L, Mosse N, Tsukerman G, Kadási L, Ravnik-Glavač M, Glavač D, Komel R, Vouk K, Kučinskas V, Krumina A, Teder M, Kocheva S, Efremov GD, Onay T, Kirdar B, Malone G, Schwarz M, Zhou Z, Friedman KJ, Carles S, Claustres M, Bozon D, Verlingue C, Férec C, Tzetis M, Kanavakis E, Cuppens H, Bombieri C, Pignatti PF, Sangiuolo F, Jordanova A, Kusic J, Radojkovič D, Sertić J, Richter D, Stavljenić Rukavina A, Bjorck E, Strandvik B, Cardoso H, Montgomery M, Nakielna B, Hughes D, Estivill X, Aznarez I, Tullis E, Tsui L.-C., Zielenski J. Characterization of a novel 21-kb deletion, CFTRdele2.3(21 kb) in the CFTR gene: a cystic fibrosis mutation of Slavic origin common in Central and East Europe. Hum Genet 2000;106:259-68.

13. Chiba-Falek 0, Parad RB, Kerem E, Kerem B. Variable levels of normal RNA in different fetal organs carrying a cystic fibrosis transmembrane conductance regulator splicing mutation. Am J Respir Crit Care Med 1999;159:1998-2002.

14. Nissim-Rafinia M, Aviram M, Randell SH, Shushi L, Ozeri E, Chiba-Falek O, Eidelman 0 , Pollard HB, Yankaskas JR, Kerem B. Restoration of the cystic fibrosis transmembrane conductance regulator function by splicing modulation. EMBO Rep 2004:5:1071-7.

15. Cremonesi L, Ferrari M, Belloni E, Magnani C, Seia M, Ronchetto P, Rady M, Russo $\mathrm{MP}$, Romeo G, Devoto M. Four new mutations of the CFTR gene $(541 \mathrm{delC}, \mathrm{R} 347 \mathrm{H}$ R3520, E585X) detected by DGGE analysis in Italian CF patients, associated with different clinical phenotypes. Hum Mutat 1992;1:314-9.

16. Nunes V, Chillon M, Dörk T, Tümmler B, Casals T, Estivill X. A new missense mutation (E92K) in the first transmembrane domain of the CFTR gene causes a benign cystic fibrosis phenotype. Hum Mol Genet 1993;2:79-80.

17. Zielenski J, Fujiwara TM, Markiewicz D, Paradis AJ, Anacleto Al, Richards B, Schwartz RH, Klinger KW, Tsui LC, Morgan K. Identification of the M1101K mutation in the cystic fibrosis transmembrane conductance regulator (CFTR) gene and complete detection of cystic fibrosis mutations in the Hutterite population. Am J Hum Genet 1993;52:609-15

18. Golla A, Deufel A, Aulehla-Scholz C, Böhm I, Hilz B, Meitinger T, Deufel T. Identification of a novel missense mutation (G314E) in exon 7 of the cystic fibrosis transmembrane conductance regulator gene identified in a CF patient with pancreatic sufficiency. Hum Mutat 1994;3:67-8.

19. Gomez Lira M, Benetazzo MG, Marzari MG, Bombieri C, Belpinati F, Castellani C, Cavallini GC, Mastella G, Pignatti PF. High frequency of cystic fibrosis transmembrane regulator mutation L997F in patients with recurrent idiopathic pancreatitis and in newborns with hypertrypsinemia. Am J Hum Genet 2000;66:2013-4.

20. Derichs N, Schuster A, Grund I, Ernsting A, Stolpe C, Kortge-Jung S, Gallati S, Stuhrmann M, Kozlowski P, Ballmann M. Homozygosity for L997F in a child with normal clinical and chloride secretory phenotype provides evidence that this cystic fibrosis transmembrane conductance regulator mutation does not cause cystic fibrosis. Clin Genet 2005:67:529-31.

21. Will K, Dörk T, Stuhrmann M, Meitinger T, Bertele-Harms R, Tümmler B, Schmidtk $\mathrm{J}$. A novel exon in the cystic fibrosis transmembrane conductance regulator gene activated by the nonsense mutation E92X in airway epithelial cells of patients with cystic fibrosis. J Clin Invest 1994;93:1852-9.

22. Aznarez I, Zielenski J, Rommens JM, Blencowe BJ, Tsui LC. Exon skipping through the creation of a putative exonic splicing silencer as a consequence of the cystic fibrosis mutation R553X. J Med Genet 2007;44:341-6.

23. Vankeerberghen A. Maturational and electrophysiological properties of CFTR proteins carrying in vitro mutagenized $R$ domains. Acta Biomedica Lovaniensia 187. Leuven, Belgium: Leuven University Press, 1998. 